\title{
Pengaruh Ability, Benevolence, dan Integrity terhadap Partisipasi $E$ - Commerce (Studi Kasus Konsumen E-Commerce di Indonesia)
}

\author{
Indirasari Cynthia Setyoparwati \\ Fakultas Ekonomi dan Bisnis, Universitas Airlangga \\ e-mail: indirasaricynthia@yahoo.com
}

\begin{abstract}
Conducting transactions through E-Commerce, including having a high enough potential risk. Therefore, consumer confidence in a vendor is needed. Being one of the important factors in the world of transactions through E-Commerce. The purpose of this study is to analyze the effect of ability, benevolence, and integrity on E-Commerce participation with a case study of E-Commerce consumers in Indonesia. Data from this study obtained 250 questionnaires distributed to ECommerce users. The statistical analysis used is multiple linear regression analysis. The ability variable is insignificant and negative for E-Commerce consumer participation. Meanwhile, benevolence and integrity variables have a significant and positive effect on E-Commerce consumer participation. This research discusses in the field of Management Information Systems and Consumer Behavior, specifically E-Commerce users. The scope of study examined is the ability, benevolence, and integrity of its influence on participation in transactions through E-Commerce.
\end{abstract}

Keywords: Ability, Benevolence, E-commerce, Integrity, Consumer Participation

\section{PENDAHULUAN}

Internet merupakan salah satu sarana elektronik yang dapat digunakan untuk berbagai aktivitas seperti komunikasi, riset, dan transaksi bisnis. Internet mulai dikenal pada tahun 1969 di Amerika Serikat, sedangkan di Indonesia mulai dikenal pada tahun 1990-an. Sejak saat itu, dunia internet mengalami yang pesat. Apalagi dengan diperkenalkannya teknologi World Wide Web (WWW), sehingga semakin menjadi sempurna dalam lingkungan teknologi internet (Mcleod dan Schell, 2004). Teknologi internet menghubungkan ribuan jaringan computer individual dan organisasi di seluruh dunia. Terdapat enam alasan mengapa internet begitu popular hingga saat ini, diantaranya memiliki konektivitas dan jangkauan yang luas; dapat mengurangi biaya komunikasi; biaya transaksi yang lebih rendah; dapat mengurangi biaya agensi; interaktif, fleksibel, dan mudah; dan memiliki kemampuan untuk mendistribusikan pengetahuan secara cepat (Laudon and Laudon, 2000).

Teknologi komunikasi, media, dan informatika telah membawa pengaruh cara dan pola kegiatan bisnis di insdustri perdagangan. Menurut data pada Asosiasi Penyelenggara Jasa Internet (APJII) mencatat angka pertumbuhan internet di Indonesia hingga tahun 2013 telah mencapai 71,19 juta orang. Penggunaan internet di Indonesia menunjukkan posisi pertama, hampir 95,75\% pengguna memanfaatkan internet untuk surat elektronik, menggeser posisi akses layanan media sosial yang mencapai 61,23\%. Hal tersebut menjadi peluang bisnis bagi beberapa pihak yang kemudian menganggap peluang dengan menyediakan atau membuat took online sebagai bagian dari $E$ Commerce. 
Hasil penelitian Liao and Cheung (2001) di Singapura, semakin banyak orang menggunakan dan memanfaatkan internet maka dia semakin senang melakukan pembelian melalui took online. Fenomena ini diharapkan dapat menjadi daya tarik bagi pengusaha, untuk mulai mengembangkan inovasi bisnis melalui E-Commerce. Terdapat banyak macam E-Commerce yang telah berkembang pada era saat ini, namun ada beberapa jenis E-Commerce yang berkembang di Indonesia, yaitu jenis marketplace. Marketplace merupakan salah satu tempat secara dari dimana penjual dapat membuat akun dan menjual barang dagangannya. Salah satu keuntungannya adalah penjual tidak perlu membuat situs atau took online pribadi. Penjual hanya perlu menyediakan foto produk dan mengunggahnya yang kemudian dilengkapi dengan deskripsi produk tersebut. Kemudian, jika ada yang ingin membeli produk tersebut, pihak penjual akan diberi notifikasi oleh sistem dari E-Commerce yang bersangkutan.

Berdasar pada hasil penelitian yang dilakukan Liao and Cheung (2001) setidaknya dengan semakin berkembangnya jumlah pengguna internet di Indonesia akan diprediksikan terus meningkatkan volume dan nilai transaksi E-Commerce.

Hal ini menyebabkan konsumen merasa mendapat jaminan keamanan dalam bertransaksi sehingga partisipasinya dalam E-Commerce menjadi meningkat jika terdapat komunikasi yang baik. Hal ini diperkuat dan disahkan oleh Undang-undang ITE Nomor 11 Tahun 2008 tentang perlindungan terhadap konsumen dan produsen atas adanya kemungkinan resiko cybercrime di Indonesia. Ada tiga pendekatan yang dapat dilakukan untuk mempertahankan keamanan di cyberspace, yaitu pendekatan teknologi, pendekatan sosial budaya dan etika, dan pendekatan hukum. Untuk mengatasi keamanan gangguan pendekatan teknologi sifatnya mutlak dilakukan, sebab tanpa suatu pengamanan jaringan akan sangat mudah disusupi atau diakses secara illegal dan tanpa hak.

Sebagai saluran transaksi pemasaran yang masih baru, E-Commerce lebih mengandung ketidakpastian dan resiko dibandingan dengan transaksi yang dilakukan secara konvensional. Potensi kejahatan biasa terjadi dalam hal transaksi online seperti penipuan, pembajakan kartu kredit, transfer dana illegal dari rekening tertentu sangatlah besar apabila sistem keamanan infrastruktur E-Commerce masih tergolong lemah (Rofiq, 2007). Sebagaimana penelitian yang dilakukan sekian banyak faktor yang dapat mempengaruhi terjadinya transaksi melalui E-Commerce, factor kepercayaan menjadi salah satu faktor yang dapat mempengaruhi. Hanya pelanggan yang memiliki kepercayaan yang berani melakukan transaksi melalui media internet.

Tanpa ada hal tersebut tidak mungkin seseorang akan melalukan transaksi di E-Commerce (Corbitt dkk., 2003; Kim and Tadisina, 2003; Pavlou and Gefen, 2004). Mayer dkk., (1995) menemukan suatu rumusan bahwa kepercayaan dibangun atas tiga dimensi, yaitu ability, benevolence, dan integrity. Tiga dimensi ini menjadi dasar penting untuk membangun kepercayaan seseorang agar dapat mempercayai suatu media transaksi. Berkaitan dengan praktik E-Commerce di Indonesia yang relatif masih baru tersebut, fenomena yang menarik untuk diteliti adalah sejauh mana ability, benevolence, dan integrity berkaitan dengan tingkat partisipasi pelanggan E-Commerce. Oleh karena itu, judul penelitian ini adalah "Pengaruh Ability, Benevolence, Dan Integrity Terhadap Partisipasi E- 
Commerce".

Permasalah yang dapat dirumuskan dalam penelitian ini adalah:

1. Bagaimana pengaruh ability terhadap partisipasi E-Commerce?

2. Bagaimana pengaruh benevolence terhadap partisipasi E-Commerce?

3. Bagaimana pengaruh integrity terhadap partisipasi E-Commerce?

\section{TINJAUAN PUSTAKA}

Teori yang terkait dalam membahas variabel yang digunakan dalam penelitian ini adalah teori TPB (Theory of Planned Behavior). Dalam penelitian ini, TPB sebagai basis teori dalam memahami perilaku konsumen. TPB dipilih dengan alasan telah terbukti dapat digunakan untuk memahami dan memprediksi perilaku manusia dalam mengadopsi teknologi (George, 2004).

TPB untuk mengatasi kekurangan pada teori sebelumnya yaitu TRA (Theory Reason of Action). Teori ini menjelaskan tentang alas an mengapa seseorang memutuskan untuk melakukan atau tidak melakukan sebuah kegiatan. TRA menjelaskan tentang hubungan niat berperilaku seseorangkan tergantung kepada sikap dan norma subjektif yang diyakini oleh orang tersebut (Fishbein and Ajzen, 1976). Model TRA berpendapat bahwa manusia membuat keputusan yang rasional berdasarkan informasi yang tersedia bagi mereka dan penentu dari perilaku seseorang (Fishbein and Ajzen, 1976). Dengan demikian, kualitas informasi yang disediakan oleh situs web E-Commerce dapat sangat mempengaruh niat seseorang untuk membeli. Jika informasi dalam E-Commerce tersebut akurat, maka akan meningkatkan kepuasan dan kepercayaan konsumen online yang akan membuat pelanggan mengambil keputusan untuk bertransaksi. Hal tersebut dapat mempengaruhi retensi konsumen atau loyalitas konsumen secara positif. Sejalan berkembangnya waktu, maka TRA telah mengalami perbaikan dan penyempurnaan. Kemudian, Mayer dkk., (1995) memperluas TRA untuk mendukung kepercayaan pelanggan.

Expectation Confirmed Theory (ECT) yang diusulkan oleh Oliver (1980) untuk mempelajari kepuasan konsumen dan perilaku pembelian kembali. ECT menyatakan bahwa konsumen pertama membentuk ekspektasi awal sebelum membeli dan kemudian membangun persepsi tentang kinerja produk atau layanan yang ditelaah dari asumsi awal. Selanjutnya, konsumen memutuskan tingkat kepuasaan mereka berdasarkan sejauh mana harapan konsumen tersebut dikonfirmasi dengan membandingkan kinerja actual atau layanan setara dengan harapan awal konsumen tersebut.

Pada akhirnya, konsumen yang merasa puas akan meniatkan untuk membeli kembali di lain waktu atau bahkan dapat memberi saran kepada kerabat terdekatnya untuk melakukan transaksi di $E$ Commerce tersebut. Saat ini, salah satu teknologi informasi yang berkembang cukup luas adalah teknologi informasi berbasis web. Pemanfaatan teknologi berbasis web dilakukan pada berbagai sektor baik dibidang pemerintahan melalui implementasi E-Government, pada bidang pendidikan melalui implementasi E-Learning, begitu juga dalam dunia bisnis dengan implementasi E-Business, Ebanking, dan E-Commerce. 
Dalam penelitian yang telah dilakukan oleh Aubert and Kelsey (2000) mengemukakan bahwa dari empat variable independen yang mempengaruhi kepercayaan adalah variable integritas yang merupakan penggerak utama bagi tumbuhnya kepercayaan terhadap konsumen. Penelitian ini menggunakan populasi mahasiswa di dua universitas di Kanada. Jumlah responden yang diperoleh sebanyak 68 mahasiswa.

Avinan and Prithwiraj (2003) meneliti mengenai model kepercayaan pada online banking. Populasi yang digunakan adalah pengguna internet dari berbagai profesi di India. Jumlah responden sebanyak 510 dari kalangan mahasiswa, professional, pegawai swasta, dan ibu rumah tangga. Hasil dalam penelitian ini menunjukkan bahwa shared value dan komunikasi memiliki pengaruh positif signifikan terhadap kepercayaan konsumen. Sedangkan, opportunistic behavior memiliki pengaruh negative terhadap kepercayaan konsumen. Shared value memiliki pengaruh signifikan terhadap kepercayaan konsumen dan memiliki pengaruh signifikan secara langsung dan tidak langsung terhadap komitmen. Selain itu, komitmen juga dipengaruhi secara signifikan oleh kepercayaan konsumen.

Ratnasingham and Kumar (2000) meneliti tentang kepercayaan mitra dagang yang berkaitan dengan partisipasi dalam E-Commerce. Penelitian ini dilakukan pada pengadopsi, implementator, manajer sistem informasi, pembeli, supplier, penghasil produk, dan distributor yang terlibat dalam transaksi E-Commerce. Teknik pengumpulan data yang dilakukan penelitian ini yaitu dengan cara kuisioner. Hasil yang diperoleh dalam penelitian adalah kepercayaan mitra dagang meningkatkan partisipasi dalam E-Commerce.

Berdasarkan latar belakang dan tinjauan pustaka yang telah dikemukakan, maka model konseptual penelitian ini adalah:

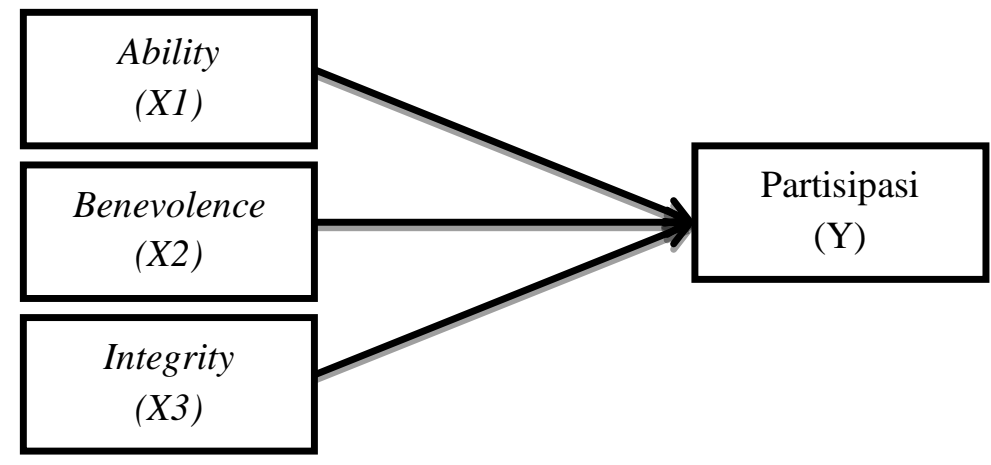

Gambar 1. Kerangka Pemikiran

Dari gambar diatas dapat dijelaskan bahwa ability, benevolence, dan integrity yang dimiliki oleh E-Commerce merupakan faktor yang membentuk kepercayaan konsumen (Mayer dkk., 1995). Apabila konsumen telah memiliki kepercayaan maka akan tumbuh partisipasi (Ratnasingham and Kumar, 2000). Kepercayan menurut Gefen and Straub (2004) merupakan suatu kesediaan untuk membuat konsumen peka terhadap tindakan yang akan diambil oleh pihak yang akan diberikan 
kepercayaan yang didasarkan pada keyakinan. Kepercayaan merupakan faktor yang penting dan salah satu faktor yang perlu diperhatikan dalam bertransaksi di E-Commerce. Salah satu bentuk partisipasi dapat berupa intensetas transaksi atau pembelian (Kim dkk., 2003).

\section{Hipotesis Penelitian}

Dari model kerangka konseptual penelitian di atas, maka hipotesis penelitian yang dikembangkan sebagai berikut:

1. Ability berkenaan dengan kemampuan E-Commerce dalam memberikan jaminan keamanan dalam proses bertransaksi. Jika konsumen percaya terhadap layanan E-Commerce tersebut untuk menjamin keamanan dalam proses transaksi, maka konsumen akan selalu berpartisipasi dalam transaksi di E-Commerce, maka:

$\mathrm{H}_{1}$ : Ability mempunyai pengaruh signifikan terhadap partisipasi E-Commerce

2. Benevolence berkenaan bahwa penjual bukan semata-mata mengejar keuntungan maksimum semata, melainkan juga memiliki perhatian yang besar dalam mewujudkan kepuasan konsumen. Jika konsumen memiliki kepercayaan akan kemauan hati E-Commerce untuk mewujudkan kepuasaan konsumen dalam proses bertransaksi, maka akan meningkatkan partisipasi konsumen dalam bertransaksi di E-Commerce, maka:

$\mathrm{H}_{2}$ : Benevolence mempunyai pengaruh signifikan terhadap partisipasi E-Commerce

3. Integrity berkenaan dengan bagaimana penjual dalam menjalan bisnisnya. Informasi yang diberikan pada konsumen apakah selalu benar atau sesuai kenyataan atau tidak. Kualitas produk yang dijual apakah sesuai realita atau tidak. Jika konsumen memiliki kepercayaan akan integritas yang dimiliki oleh E-Commerce dalam melaksanakan atau menjalankan bisnis online. Maka, konsumen akan terus meningkatkan partisipasi dalam belanja di E-Commerce, maka:

$\mathrm{H}_{3}$ : Integrity mempunyai pengaruh signifikan terhadap partisipasi E-Commerce

\section{METODE PENELITIAN}

Ruang lingkup penelitian ini adalah dalam bidang sistem informasi manajemen dan perilaku konsumen, khususnya pada aplikasi E-Commerce di Indonesia. Lingkup bahasan yang diteliti adalah ability, benevolence, dan integrity bagaimana pengaruhnya terhadap partisipasi dalam transaksi ECommerce. Subyek yang digunakan dalam penelitian ini adalah semua pengguna internet di Indonesia yang mempunyai pengalaman dalam melakukan transaksi pembelian barang atau jasa melalui media E-Commerce. Barang atau jasa yang dibeli harus berasal dari vendor atau penjual yang ada di Indonesia, tanpa membatasi jenis barang atau jasa yang dibeli. Penelitian ini merupakan penelitian survei, yaitu penelitian yang mengambil sampel secara langsung dari populasi. Dilihat dari permasalahan yang diteliti, penelitian ini merupakan penelitian kausalitas, yang bertujuan untuk menganalisis hubungan dan pengaruh (sebab-akibat) dari dua atau lebih fenomena melalui pengujian hipotesis (Sekaran and Bougie, 2016). 
Data dari penelitian ini diperoleh dari kuesioner yang didistribusikan kepada para pengguna ecommerce dari berbagai daerah. Teknik pengambil ansampel dalam penelitian ini adalah nonprobabilitas yang dipilih adalah teknik jugemental (purposive) (Sekaran and Bougie, 2016). Teknik ini dipilih untuk memastikan bahwahan yasampel yang memiliki unsure tertentu yang telah ditetapkan oleh peneliti yang akan diambil sebagai sampel. Dalam penelitianini jumlah respondense banyak 250 responden.

Variabel bebas yang digunakan dalam penelitian ini, antara lain:

1. Ability: sebagai persepsi konsumen tentang kemampuan penjual melalui media E-Commerce dalam menyediakan barang, memberikan rasa aman dan nyaman kepada konsumen dalam melakukan kegiatan transaksi barang maupun jasa. Indikator yang digunakan untuk mengukur variabel ini adalah kompetensi $\left(\mathrm{X}_{1.1}\right)$ persepsi konsumen bahwa vendor E-Commerce mempunyai kemampuan dalam menyediakan barang yang berkualitas bagi konsumen, pengalaman $\left(\mathrm{X}_{1.2}\right)$ persepsi konsumen bahwa vendor E-Commerce mempunyai pengalaman sehingga mampu mengirim barang tepat pada waktunya ke konsumen, pengetahuan luas $\left(\mathrm{X}_{1.3}\right)$ persepsi konsumen bahwa vendor E-Commerce memiliki pengetahuan yang baik dalam mengamankan transaksi, pengesahan institusional $\left(\mathrm{X}_{1.4}\right)$ persepsi konsumen bahwa vendor E-Commerce telah diakui keberadaannya oleh pihak lain, sebagai contoh supplier, distributor, dan jasa ekspedisi.

2. Benevolence: sebagai persepsi konsumen terhadap keinginan baik penjual melalui media ECommerce dalam memberikan kepuasan transaksi. Indikator yang digunakan adalah perhatian $\left(\mathrm{X}_{2.1}\right)$ persepsi konsumen bahwa vendor E-Commerce memiliki perhatian untuk memberikan pelayanan terbaik untuk konsumen, kemauan berbagi $\left(\mathrm{X}_{2.2}\right)$ persepsi konsumen bahwa vendor $E$ Commerce memiliki kemauan untuk memberikan keuntungan bagi konsumen, dapat diharapkan $\left(\mathrm{X}_{2.3}\right)$ persepsi konsumen bahwa vendor E-Commerce memiliki itikad baik untuk memberikan kepuasan kepada konsumen.

3. Integrity: sebagai persepsi konsumen mengenai komitmen penjual melalui media E-Commerce dalam menjaga nilai-nilai untuk memberikan pelayanan terbaik kepada konsumen. Indikator untuk mengukur variabel adalah pemenuhan $\left(\mathrm{X}_{3.1}\right)$ persepsi konsumen bahwa vendor $E$ Commerce akan memenuhi apa yang diharapkan konsumen, kejujuran $\left(\mathrm{X}_{3.2}\right)$ persepsi konsumen bahwa vendor E-Commerce tidak akan menyembunyikan informasi penting untuk konsumen, kehandalan $\left(\mathrm{X}_{3.3}\right)$ persepsi konsumen bahwa vendor E-Commerce selalu menjaga reputasi untuk konsumen.

Variabel terikat yang digunakan dalam penelitian ini adalah partisipasi. Partisipasi didefinikan sebagai intensitas konsumen dalam melakukan transaksi melalui E-Commerce. Indikator yang digunakan untuk mengukur variable yaitu keberlanjutan $\left(\mathrm{Y}_{1.1}\right)$ persepsi konsumen bahwa konsumen akan terus melakukan transaksi (intention to purchase) melalui E-Commerce, Frekuensi ( $\left.\mathrm{Y}_{1.2}\right)$ persepsi konsumen bahwa konsumen akan terus meningkatkan frekuensi bertransaksi melalui E-Commerce, 
rekomendasi $\left(\mathrm{Y}_{1.3}\right)$ persepsi konsumen bahwa konsumen akan merekomendasikan kepada pihak lain seperti rekan agar melakukan transaksi melalui E-Commerce.

\section{HASIL DAN PEMBAHASAN PENELITIAN}

Agar dapat mengetahui kevali dan hubungan antar variabel yang digunakan dan diuji dalam penelitian ini, langkah pertama yang dilakukan yaitu uji asumsi klasik. Hasil dari uji asumsi klasik, sebagai berikut:

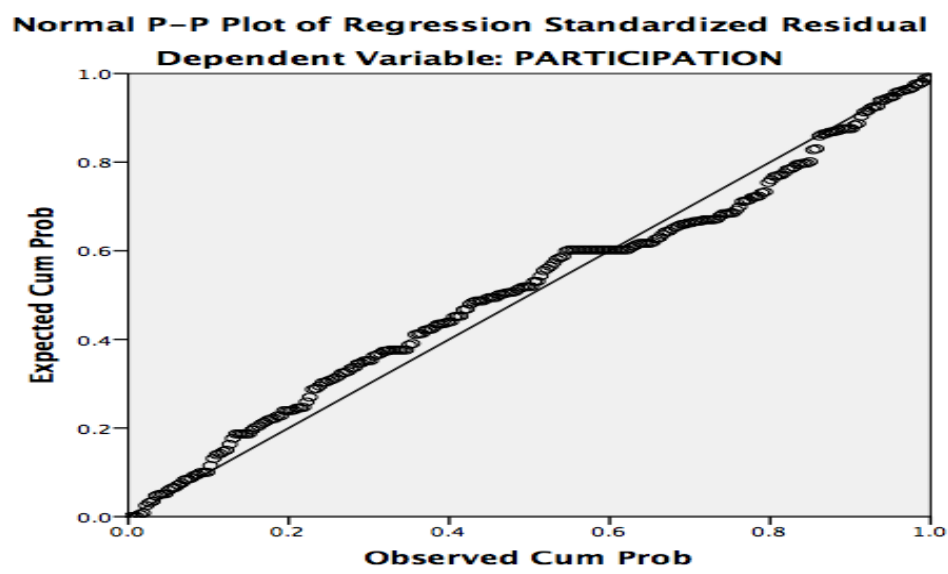

Gambar 2. Hasil Uji Normalitas

Uji Normalitas bertujuan untuk menguji apakah model regresi linier berganda, variable bebas dan variable terikat mau pun keduanya mempunyai distribusi normal atau tidak. Model regresi yang baik adalah data berdistribusi dengan normal atau mendekati normal. Dari gambar di atas, dapat dilihat bahwa titik menyebar di sekitar garis diagonal. Penyebarannya mengikuti dan mendekati arah garis diagonal. Maka, data variable terikat dan variable bebas yang digunakan dalam penelitian ini berdistribusi normal dan memenuhi asumsi normalitas.

Tabel I. Hasil Uji Multikolinearitas

\begin{tabular}{lcc}
\hline VARIABEL & TOL & VIF \\
\hline Integrity & 0,954 & 1,049 \\
Benevolence & 0,843 & 1,186 \\
Ability & 0,878 & 1,138 \\
\hline
\end{tabular}

Sumber: Data Diolah, 2019

Uji multikolinearitas bertujuan untuk menguji apakah model regresi yang digunakan ditemukan adanya korelasi antar variable bebas. Untuk mengetahui ada atau tidaknya multikolinearitas dapat dilihat dari nilai toleransi yang mendekati 1 dan nilai Variance Inflation Factor (VIF) tidak lebih dari 10. Berdasarkan table di atas, hasil uji multikolinearitasdiketahuibahwanilaitolerance masingmasing variable bebas memiliki nilai tolerance tidak lebih dari angka 1. Sedangkan, nilai Variance Inflation Factor (VIF) dari masing-masing variable bebas memiliki nilai tidak lebih dari angka 10. Dapat disimpulkan bahwa nilai tolerance dan nilai VIF daritabel di atas berada dalam nilai yang memenuhi asumsi bahwa tidak terjadi masalah multikolinearitas. 


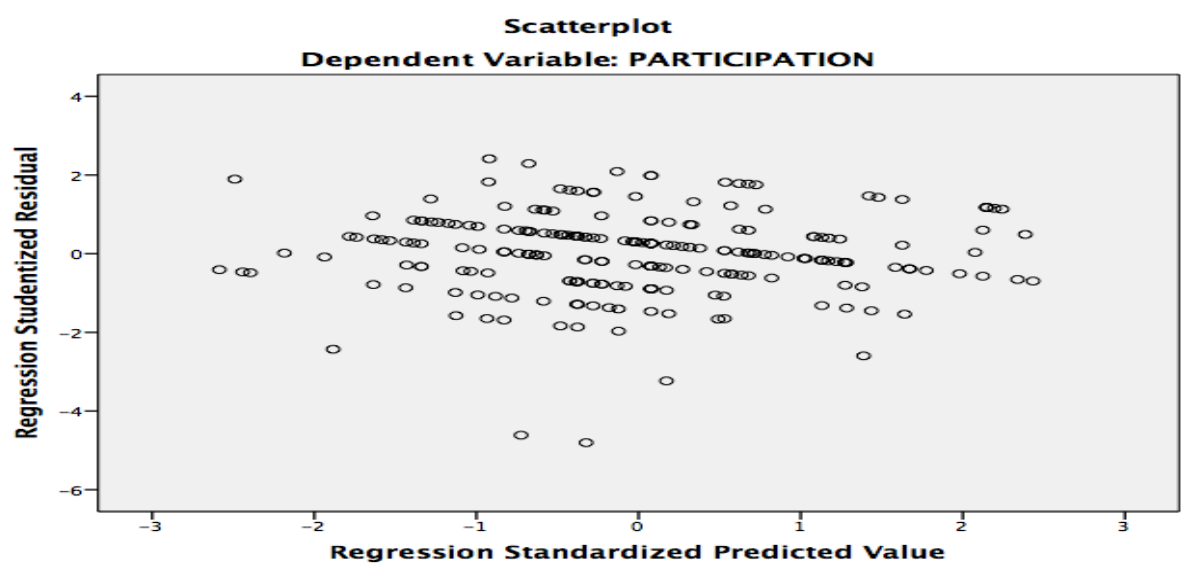

Gambar 3. Hasil Uji Heterokedastisitas

Uji heterokedastisitas bertujuan untuk menguji apakah dalam sebuah model regresi linier terjadi ketidaksamaan varians dari residual suatu pengamatan ke pengamatan yang lain. Model regresi dapat dikatakan baik jika tidak terjadi heterokedastisitas dalam model regresi tersebut. Dari gambar pola Sctterplot diatas, dapat diketahui bahwa titik-titik data menyebar di atas dan di bawah angka 0 dan penyebaran titik-titik tidak membentuk pola tertentu. Maka dapat disimpulkan bahwa dalam model regresi ini tidak terjadi heteroskedastisitas.

Analisis regresi berganda digunakan untuk menghitung besarnya pengaruh antara variabel bebas terhadap variabel terikat. Dalam penelitian ini alat bantu mengguakan program SPSS diperoleh hasil sebagai berikut:

Tabel 2. Hasil Perhitungan Regresi Linier Berganda

\begin{tabular}{lccc}
\hline \multicolumn{1}{c}{ Model } & B & t & Sig. \\
\hline (Constant) & 5.776 & 5,130 & 0,000 \\
Ability & $-0,033$ & $-0,693$ & 0,489 \\
Benevolence & 0,210 & 3,618 & 0,000 \\
Integrity & 0,316 & 4,251 & 0,000 \\
\hline $\mathrm{R}$ & 0,374 & & \\
$\mathrm{R}^{2}$ & 0,140 & & \\
Adjusted $\mathrm{R}^{2}$ & 0,129 & & \\
F & 13,316 & & \\
Sig. F & 0,000 & & \\
\hline
\end{tabular}

Sumber: Data diolah, 2019

Berdasarkan hasil pada tabel di atas dapat diperoleh persamaan regresi linier berganda sebagai berikut:

$$
Y=5.776-0,033 X_{1}+0,210 X_{2}+0,316 X_{3}+e
$$

Uji $\mathrm{F}$ dilakukan guna untuk mengetahui pengaruh variable bebas secara bersama-sama terhadap variable terikat. Dari hasil tabel di atas dapat dilihat bahwa sig F > 5\% (13,316 > 0,05) maka variabel ability, benevolence, dan integrity secara bersama - sama berpengaruh signifikan terhadap partisipasi E-Commerce. Jadi, dapat disimpulkan bahwa $\mathrm{H}_{0}$ diterima.

Nilai koefisien determinasi berganda $\left(\mathrm{R}^{2}\right)$ digunakan untuk mengetahui besarnya sumbangan dari variable bebas terhadap variable terikat. Nilai koefisien determinasi terletak antara 0 dan 1 . 
Apabila $\mathrm{R}^{2}=1$, maka garis regresi dari model tersebut memberikan sumbangan sebesar $100 \%$ terhadap perubahan variable terikat. Apabila $\mathrm{R}^{2}=0$, maka model tersebut tidak bisa mempengaruhi atau tidak bisa memberikan sumbangan terhadap perubahan variabel terikat. Kecocokan model akan semakinlebih baik apabila mendekati angka 1 .

Berdasarkan hasil analasis pada tabel 2, bisa dilihat bahwa hasil koefisien determinasi berganda $\left(\mathrm{R}^{2}\right)$, dilihat dari Adjusted $R$ Square sebesar 0,129 hal ini berarti 12,9\% perubahan partisipasi E-Commerce dapat dijelaskan oleh variable ability, benevolence, dan integrity. Sedangkan, sisanya sebesar 87,1\% disebabkan oleh faktor lain yang tidak termasuk dalam penelitian ini.

Kemudian, hasil perhitungan uji t dapat di lihat pada tabel 2. Berdasarkan pada tabel tersebut dapat diketahui besarnya pengaruh masing-masing variabel bebas terhadap variabel terikat, sebagai berikut:

1. Pengaruh variabel ability terhadap partisipasi E-Commerce

Pada tabel 1 menunjukkan bahwa hasil sig t>0,05 $(0,489>0,05)$ dengan asumsi $\mathrm{X}_{2}$ dan $\mathrm{X}_{3}$ konstan. Karena sig $\mathrm{t}<0,05$, maka dapat diartikan bahwa secara parsial tidak berpengaruh signifikan terhadap partisipasi E-Commerce.

\section{Pengaruh variabel benevolence terhadap partisipasi E-Commerce}

Pada tabel 1 menunjukkan bahwa hasil sig $\mathrm{t}<0,05(0,000<0,05)$ dengan asumsi $\mathrm{X}_{1}$ dan $\mathrm{X}_{3}$ konstan. Karena sig $\mathrm{t}<0,05$, maka dapat diartikan bahwa secara parsial berpengaruh signifikan terhadap partisipasi E-Commerce.

3. Pengaruh variabel integrity terhadap partisipasi E-Commerce

Pada tabel 1 menunjukkan bahwa hasil sig $t<0,05(0,000<0,05)$ dengan asumsi $\mathrm{X}_{1}$ dan $\mathrm{X}_{2}$ konstan. Karena sig $\mathrm{t}<0,05$, maka dapat diartikan bahwa secara parsial berpengaruh signifikan terhadap partisipasi E-Commerce.

Setelah dilakukan pengujian statistik secara parsial maupun secara simultan, maka analisis selanjutnya dilihat dari hasil analisis regeresi, sebagai berikut:

\section{Pengaruh variabel ability terhadap partisipasi E-Commerce}

Dalam hasil analisis regresi pada tabel 1 menunjukkan bahwa variabel ability negatif dan tidak berpengaruh signifikan terhadap partisipasi E-Commerce pada studi kasus konsumen E-Commerce di Indonesia dengan nilai koefisien -0,033. Hal ini dapat diartikan bahwa faktor ability yang diukur melalui kompetensi, pengalaman, pengetahuan, dan pengesahan institusional bukan termasuk faktor yang dapat menentukan partisipasi konsumen E-Commerce di Indonesia. Temuan ini tidak sejalan dengan temuan pada penelitian yang dilakukan oleh Gefen dan Straub (2004) dimana ability mempunyai pengaruh positif dan signifikan terhadap keberlanjutan pembelian (purchase intentions) yang merupakan salah satu indikator dari konstruk partisipasi yang diukur dalampenelitian ini. Ability vendor dalam menyediakan, melayani, sampai mengamankan transaksi dari gangguan pihak lain. Artinya bahwa konsumen memperoleh jaminan kepuasan dan keamanandari penjual dalam melakukan transaksi. 


\section{Pengaruh variabel benevolence terhadap partisipasi E-Commerce}

Variabel benevolence berpengaruh positif dan signifikan terhadap partisipasi E-Commerce di Indonesia. Hal ini berarti faktor benevolence yang diukur melalui perhatian, kemauan berbagi, dan dapat diharapkan merupakan suatu faktor yang menentukan partisipasi konsumen E-Commerce di Indonesia. Dan menjadi bahan pertimbangan untuk vendor yang terkait untuk meningkatkan partisipasi. Hasil ini sejalan dengan hasil penelitian yang dilakukan oleh Gefen dan Straub (2004) dimana benevolence vendor mempunyai pengaruh positif dan signifikan terhadap keberlanjutan pembelian (purchase intentions) yang merupakan salah satu indikator dari konstruk partisipasi. Benevolence merupakan kemauan penjual dalam memberikan kepuasan yang saling menguntungkan antara dirinya dengan konsumen. Profit yang diperoleh penjual dapat dimaksimumkan, tetapi kepuasan konsumen juga tinggi. Penjual bukan semata-mata mengejar profit maksimum semata, melainkan juga memiliki perhatian yang besar dalam mewujudkankepuasan konsumen.

3. Pengaruh variabel integrity terhadap partisipasi E-Commerce

Variabel integrity berpengaruh positif dan signifikan terhadap partisipasi pelanggan E-Commerce di Indonesia. Hal ini dapat diartikan faktor integrity yang diukur melalui pemenuhan, kejujuran, dan kehandalan merupakan suatu faktor yang dapat menentukan partisipasi pelanggan E-Commerce di Indonesia.Temuan ini mendukung penelitian Gefen dan Straub (2004)di mana integrity mempunyai signifikan terhadapkeberlanjutan pembelian (purchase intentions) yang merupakan salah satu indikator dari konstruk partisipasi.

\section{KESIMPULAN DAN SARAN}

Berdasarkan hasil dan pembahasan yang telah dijelaskan, maka kesimpulan dalam penelitian ini adalah variabel ability tidak berpengaruh signifikan dan negatif terhadap partisipasi E-Commerce di konsumen Indonesia. Hal ini berarti faktor ability tidak menjadi penentu untuk partisipasi ECommerce di Indonesia. Tetapi, ada dua variabel lain yang dapat menjadi penentu untuk variable partisipasi E-Commerce yaitu benevolence dan integrity. Variabel benevolence berpengaruh signifikan dan positif terhadap partisipasi E-Commerce konsumen di Indonesia, hal ini merupakan suatu faktor menentukan partisipasi konsumen dan menjadi informasi penting untuk supplier agar menjadi tolak ukur yang penting untuk meningkatkan partisipasi konsumen dalam dunia E-Commerce.

Variabel integrity juga berpengaruh signifikan dan positif terhadap partisipasi E-Commerce. Faktor integrity yang diukur melalui pemenuhan, kejujuran, dan kehandalan merupakan suatu faktor yang menentukan partisipasi pada konsumen E-Commerce di Indonesia. Selain itu, menjadi factor penting yang dapat dipertimbangkan agar dapat meningkatkan partisipasi konsumen E-Commerce di Indonesia.

Beberapa saran yang dapat menjadikan implikasi bagi penelitian selanjutnya yang memliki kaitan dan juga untuk para vendor, yaitu sebaiknya para vendor atau pemilik E-Commerce mampu 
memberikan perhatian terhadap para konsumen, serta memberikan keuntungan dan pelayan yang memuaskan, sehingga keuntungan bisa meningkat melalui membuat fanpage tersendiri khusus para konsumen E-Commerce tersebut agar dapat memberikan timbale balik yang positif secaralangsung kepada pemilik E-Commerce sehingga lebih memahami keinginan dan keluhan tiap para konsumen. Dan diharapkan para vendor jujur dalam menjual setiap produk yang dijual terhadap konsumen,serta menjaga reputasinya dihadapan para pelanggan guna meningkatkan keuntungan penjualan dengan menjelaskan suatu barang atau jasa sesuai dengan kenyataan yang ada serta tetap bersikap professional dengan menghargai tiap konsumen.

\section{REFERENSI}

Aubert, B., and Kelsey, B. L. 2000. The Illusion of Trust and Performance.

Avinandan, M., and Prithwiraj, N. 2003. A Model of Trust in Online Relationship Banking. The International Journal of Bank Marketing. 21(1), 5-15.

Corbitt, B. J., Thanasankit, T., and Yi, H. 2003. Trust and E-Commerce: A Study of Consumer Perceptions. Electronic Commerce Research and Applications. 2(3), 203-215.

Fishbein, M., and Ajzen, I. 1976. Misconceptions about the Fishbein Model: Reflections on a Study by Songer-Nocks. Journal of Experimental Social Psychology. 12(6), 579-584.

Gefen, D., and Straub, D. W. 2004. Consumer trust in B2C e-Commerce and the importance of social presence: experiments in e-Products and e-Services. Omega. 32(6), 407-424.

George, J. F. 2004. The Theory of Planned Behavior and Internet Purchasing. Internet Research. 14(3), 198-212.

Kim, D. J., Ferrin, D. L., and Rao, H. R. 2003. Antecedents of Consumer Trust in B-to-C Electronic Commerce.

Kim, E., and Tadisina, S. 2003. Customers' Initial Trust in E-Businesses: How to Measure Customers' Initial Trust. AMCIS 2003 Proceedings. 5.

Laudon, K. C., and Laudon, J. P. 2000. Management Information Systems: Organization and Technology in the Networked Enterprise (6th ed.). New Jersey: Prentice Hall International.

Liao, Z., and Cheung, M. T. 2001. Internet-Based E-Shopping and Consumer Attitudes: An Empirical Study. Information and Management. 38(5), 299-306.

Mayer, R. C., Davis, J. H., and Schoorman, F. D. 1995. An Integrative Model of Organizational Trust. Academy of management review, 20(3), 709-734.

Mcleod, R., and Schell, G. 2004. Management Information System (9th ed.). New Jersey: Prentice Hall.

Oliver, R. L. 1980. A Cognitive Model of the Antecedents and Consequences of Satisfaction Decisions. Journal of Marketing Research. 17(4), 460-469.

Pavlou, P. A., and Gefen, D. 2004. Building Effective Online Marketplaces with Institution-Based Trust. Information Systems Research. 15(1), 37-59.

Ratnasingham, P., and Kumar, K. 2000. Trading Partner Trust in Electronic Commerce Participation. ICIS 2000 Proceedings. 56.

Rofiq, A. 2007. Pengaruh Dimensi Kepercayaan (Trust) terhadap Partisipasi Pelanggan Ecommerce. Universitas Brawijaya Malang.

Sekaran, U., and Bougie, R. 2016. Research Methods for Business: A skill Building Approach: John Wiley and Sons. 